\title{
A MEMÓRIA NA RECONSTRUÇÃO DA HISTÓRIA DA EDUCAÇÃo
}

\author{
Marta Coutinho Caetano \\ Instituto Federal de Educação Ciência e Tecnologia do Pará (IFPA) \\ coutinhomarta23@gmail.com
}

\section{RESUMO}

Este artigo é parte da pesquisa de Mestrado em História e Memória da Educação, em curso, realizada pelo programa de Pós-Graduação da Universidade Federal do Ceará, este estudo retratará sobre a utilização da memória para reconstrução da história de educação, retratando a educação na Amazônia Paraense, focando a educação para diversidade, seja na escola, ou na prática da cotidianada pesca. Tem por objetivos, analisar as narrativas orais, de pescadores artesanais, para entender a história de educação em sua localidade e identificar quais saberes e práticas foram utilizadas para ensinar e aprender, seja na escola, ou na atividade pesqueira. As ilhas Tabatinga e Sirituba, na região de Abaetetuba Pará, estão sendo utilizadas como lócus da pesquisa. A análise da pesquisa é construída em dois momentos. (i) análise documental da localidade e região, (ii) registro das narrativas orais, sobre conhecimentos e prática educacional, utilizando-se do método história de vida. Possibilitou, um caráter singular dado a história da educação na ilha, no qual pescadores consideram importantes a educação, mas admitem que sempre aprenderam com a vida e natureza. E hoje, pensam a escola dentro da ilha, como fonte de transformação e formação para seus filhos.

Palavras-chave: Pescadores, Memória, Educação

\section{THE MEMORYIN THERECONSTRUCTIONOF THE HISTORY OFEDUCATION ABSTRACT}

\begin{abstract}
This article is part of research in History and Memory Master of Education, currently held by the Graduate Program, Federal University of Ceará, this article reports on the use of memory for reconstructing the history of education, education in portraying Amazon Paraense, Focusing on education for divert, whether in school or in the practice of everyday fishing. It aims to analyze the oral histories of fishermen to understand the history of education in their locatily and to identify what knowledge and practices were used for teavhing and learning, whether at school,or fishing. Sirituba e Tabatinga and the islands in the region of Pará Abaetetuba, are being used as a locus of research. Analysis of the research is constructed in two stages. (i) documentary analysis of the locality and region, (ii) recording of oral narratives on knowledge and educational practice, using life history method. Enabled, a unique character given the history of education in the island where fishermen consider important, but admit that they were taught about life and nature. And today, they think the school within the island as a source of transformation and education for their sons.
\end{abstract}

Keywords: Fishermen, Memory, Education 


\section{Introdução}

A história da educação ribeirinha é recontada através das memórias de pescadores que em meio a rios, fauna e flora, no silêncio das águas, sob influências climáticas de grandes ou baixas marés, falam de educação, e através dessas narrativas reconstroem e ressignificam saberes necessários para ensinar e aprender. Sendo Abaetetuba uma região histórica e cultural para o Estado do Pará, além possuir uma área de forte influência pesqueira e com o número expressivo de moradores ribeirinhos, a educação nas ilhas faz-se presente, entretanto é no contexto das memórias, quetenta-se reconstruir a história da educação em um dos arquipélagos amazônicos de saberes."Lembram muito o que não viveram diretamente. Um artigo de noticiário, por exemplo, às vezes se torna parte da vida de uma pessoa. Daí, pode-se descrever a memória como uma reconstrução do passado".(BURKE, 2000, p.70).

Atualmente segundo, dados estatísticos da Secretaria Municipal de Educação do município, nas ilhas, a divisão das turmas, é feita por Educação Infantil, Ensino Fundamental e EJA ( Multi Seriado e Multi Etapa. Para ribeirinhos, o ensino da turma, " a multissérie oportuniza o apoio mútuo e a aprendizagem compartilhada, a partir da convivência mais próxima estabelecida entre estudantes". (HAGE, 2005, p.46)

É no contexto de educação, como prática educativa, o presente artigo, discorre sobre memórias e experiências de docentes e pescadores, sobre a prática educativa, de como ensinar e aprender em regiões, nas quais a vida e orientada pelas marés. Fontes primárias de reconstrução deste passado educacional são escassas, e quase inexistentes, neste sentido as histórias orais, e histórias de vidas, faze-ão presentes no auxílio da reconstrução da história educacional na Amazônia.

A construção da memória local poderá transmitir a configuração em elemento essencial dentro do que chamamos de identidade, ou identidades, sejam elas individuais ou coletivas cuja busca é uma das atividades fundamentais do indivíduo nas sociedades de hoje, para registrar seus conhecimentos sócios históricos sobre a região, e seus saberes, em forma de documentos escritos.

Estudar as narrativas de pescadores, uma vez que estes se encontram em convívio diário, com a ambiente natureza, e apresentam a labuta diária e constante, de quem retira das águas o sustento necessário a sua sobrevivência.O contato mais direto ao ensinar, dá dinamicidade ao ensino multisseriado, pois ao se relacionarem, os alunos trocam experiências e saberes que poderão traduzir uma aprendizagem coletiva, pórem este fato isolado, não é indicativo para um ensino de qualidade. Pórem considera-se um avanço educacional na Ilha, pois somente no presente a educação fez presente na localidade como demonstra a afirmação a seguir:

"As escolas multisseriadas oportunizam às populações do campo terem acesso à escolarização no lugar em que vivem, em sua própria comunidade, fator que podeira contribuir siginificativamente para permência dos sujeitos no campo $^{1}$ e para afirmação de suas identidades culturais. A escola localizada no próprio espaço em que vivem e convivem os sujeitos do campo pode constitui-se num centro de desenvolvimento cultural da comunidade, envolvendo a todos". (HAGE, 2005) 
Ao falar da permanência desses sujeitos no campo, o ensino de pescadores, na localidade, proporciona, que estes trabalhadores, dependentes da água e das marés para realização de seu trabalho, agora possam estar em contato com a educação formal.

\section{Memória de pescador: A história da educação na visão dos pescadores}

Uma das funções principais do historiador da educação é compreender esta lógica, de múltiplas identidades, por meio da qual se definem memórias e tradições. $\mathrm{Na}$ construção da história os atores são sujeitos sociais, dotados de opiniões, segundo ARANHA (2006, p. 28).

Ao se fazer um levantamento sobre dados referentes a história de um lugar, observa-se como esta deixa marcas na população local, e ao se falar em educação na Amazônia, ou melhor dizer, na construção social, os sujeitos inseridos no contexto das águas, traduzem suas experiências com seu modo de viver, e através de suas vivências com a natureza, representam e demonstram sua religiosidade e misticismo, os quais devem ser respeitados e analisados na concepção de troca de saberes, sobre comunidade e pesquisadores.

No ato de relembrar suas memórias o pescador, vai de fato externalizar, não apenas suas vivências, mas as aprendizagens ao longo da vida, o que de significativo aprendeu, e como aprendeu como ele transmitiu conhecimentos, e o que de fato foi a educação para ele, nestas linhas retratarei a Educação na memória de seu Paulo e seu Dário. Ambos conhecedores da região. Que estudaram em períodos e locais diferentes da Ilha. Um no final da década de 40 e o outro na década de 70. Entretanto, como podem períodos distintos, convergirem em aspectos históricos da educação. A memória é sim, um trabalho sobre o tempo, mas sobre o tempo vivido, conotado pela cultura e pelo indivíduo (BOSI, 2003.p.53) .

Todavia, pensar na memória coletiva, aproxima fragmentos espaciais da realidade, em alguns momentos comparados as fontes primárias, pórem em outros, valem-se das lembranças. Uma vez, que nestes lugares o termo "desemburrar", fazia parte não só, da lidar diária, mas de elementos do contexto educacional. Não haviam Boletins,e quaisquer outros registros educacionais. Inexistentes. Reflexos de uma educação, baseada, na primeiras letras. E quais letras seriam estas? As que se apresentavam em cartilhas e livros. Haviam, metodologias específicas, para professor mostrar aos alunos como faziam cálculos matemáticos, justificados pela prova dos nove. A tabuada, decorada, traduzia, o rigor.

Morador a mais de 40 anos da comunidade, Seu Paulo, pescador Seu Paulo trabalha na pesca artesanal ${ }^{2}$, nos conta o que foi e o que representa para ele a educação formal. E como, hoje ele a ver para formação de seus filhos.

“... Eu ia buscar meu professor, pra me desemburrar,mas era complicado. A gente, tinha e ainda tem uma lida pesada na pesca, eu estudava, mas não aprendia muito! Hoje, é bom ter uma escola aqui dentro da Ilha pra os filhos da gente estudar. _! Sabe, eu me orgulho de ter ajudado a fazer uma escola pra meus filhos, pois não aguentava ver, minha menina sofrendo com dor no peito. Por quê pra chegar na 
escola, us meninos se embrenhavam nessa lama, pra chegar até a casa da professora Inês! E cando! A maré darva arta! Eles chegavam aqui" todo molhado. Muitas vezes, nós estava pescando e não tinha como busca, eles pela beira da Ilha pra não se molharem..."

A realidade educacional para muitos ribeirinhosda comunidade Tabatinga é retratada, desta forma. BOSI (2007) O tempo da memória é social, não só porque é o calendário do trabalho e da festa, do evento político e do fato insólito, mas também porque repercute no modo de lembrar. Uma lembrança pessoal que marca, e dar direito ao pai querer educar, e com seu próprio trabalho organizar espaços para aprendizagens de seus filhos.

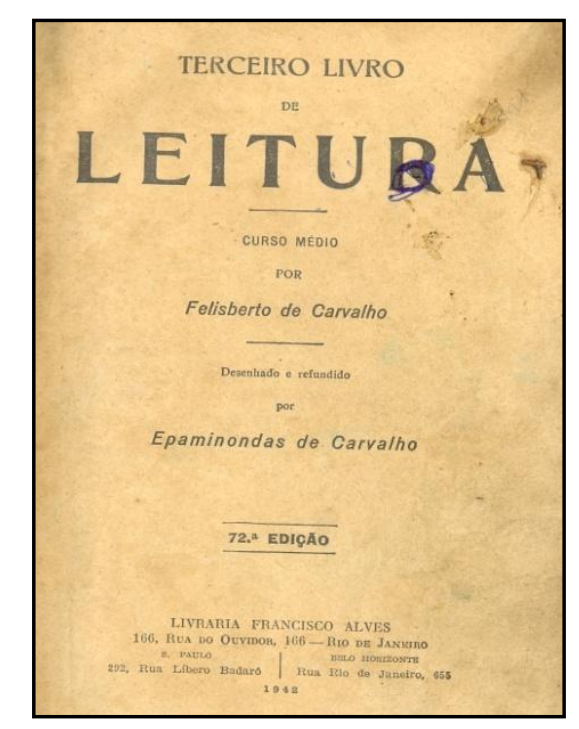

Fonte: Documentos pessoais de Seu Dário

Seu Dário, um pescador aposentado por conta das dores na costa, Com seus 81 anos mostra com saudosismo, Olivro em que estudou na década de 40, já iniciando a década de 50, ele guarda com carinho, o livro no qual aprendeu.

Segundo Seu Dário “_: nós prendia o abecedário, e despois, aprendia os livro de leitura! Eu estudava, tinha todas as matérias!!! "A memória, onde cresce a história, que por sua vez a alimenta, procura salvar o passado para servir o presente e o futuro".(LE GOFF, 1994, p.477)

Mesmo, com o estudo nos livros, não havia boletins, logo mesmo que aprendesse, não haviam documentos escritos que comprovassem a educação formal, uma vez que seu Dário também, aprendia com professores intinerantes, que uma vez ao ano, iam no barracão de palha da comunidade para ensinar.

Mas para o pescador, seu livro foi seu companheiro inseparável desde os 10 anos de idade. .Da aprendizagem sistematizada,no certo e errado, no sim e no não.Mas como tecer fontes tão memorialísticas em contexto, educacional. É que tentamos desenvolver e expor a possibilidade. Nessas Ilhas, só chegavam-se a barco, era difícil a acolhida a área educacional. "As memórias são maleáveis, e é necessário compreender como são concretizadas, e por quem, assim como os limites dessa maleabilidade".(BURKE, 2000, p.73). 


\section{Memória Docente}

Ensinar, nas Ilhas, requer responsabilidade e dedicação. Iremos navegar nas memórias de Dila, moradora da ilha Sirituba, há mais de 30 anos. Ela nos conta como aprendeu e como ensina na localidade. E por ser moradora da Ilha, desde menina, a prática na sala de aula, é mais interativa, pois alguns são seus conhecidos, outros parentes, e outros colegas de profissão, logo, ensinar envolve a troca de saberes entre educador e educando numa relação dialógica, em que ambos aprende e apreendem com a prática, do cotidiano ou de sala de aula. Moradora da Ilha de Sirituba emAbaetetuba Pará.

Mulher de traços finos, mais coma firmeza, de conhecimentos sobre educação e pesca que reconstrói uma história de educação na Amazônia paraense, a delicadeza, de mãe, esposa, professora, e pescadora, a faz conduzir, todos os dias, em sua canoa, o desejo de ensinar e aprender. Dila conta, que sua caminhada na educação, foi difícil! E assim foi, como muito ribeirinhos, que sem acesso a escola nas Ilhas Dila, conseguiu concluir o ensino médio em magistério. A riqueza da pesca na região é evidenciada, pórem a professora afirma "pra você ser pescadora, você tem que saber como colocar, sua rede, como arredar no final do dia, colocar o matapi, pra pescar camarão, e isso não é o suficiente se a maré for de lanço, aí não da pra nada, é colocar e tirar o matapi do jeito que entrou na água."... [“ taqui! meu matapi, eu que fiz]"

$\mathrm{Na}$ afirmação acima, a professora, demonstra, parte do cotidiano da pesca e de como é difícil a educação nas ilhas, é há recorte da substância social da memória como menciona BOSI, nos mostra que o modo de lembrar é individual, tanto como social, descrevendo aspectos do cotidiano da pesca, que cedo o pescador, vai ao comércio, para venda da pesca do dia anterior.

As expressões da pescadora, remotam conhecimentos sobre a pesca, o contexto geográfico, ao falar de rabeta (canoa motorizada, de pequeno porte, comum na região, para tráfego de pessoas e mercadorias. E matapi ( armadilha em forma de cone cilindro, que se assemelha como o covo do Nordeste, pois é fechada por dois cones, sendo que cada lado contém uma abertura em forma de funil para que o camarão entre e não consiga sair. A matéria-prima para sua construção são talas de jupati ( Raphia taedigera), uma palmeira da floresta amazônica. O tipo de tala é um dos fatores que a difere do covo do Nordeste. A distância entre as talas tem finalidade de classificação do tamanho do camarão que se pretende deixar preso. A farinha de babaçu é utilizada como isca; coloca-se uma porção de farinha envolvida numa folha para a armação da boneca, denominação dada pelos ribeirinhos à isca pronta a ser utilizada. A pesca com o matapi é realizada tanto em águas interiores como no litoral; na primeira, seu uso é mais intenso, quase o ano todo, enquanto que em águas salgadas seu uso limita-se ao período de safra do camarão. ( MORAES,2007 p. 54-55)

Já a maré de lance (grandes máres, que na região amazônica, elas vêm com força de ventos no período de janeiro a março, impedindo que pequenos crustáceos como o camarão, sejam aprisionados nos matapis).

"A cultura como conhecimento e o conhecimento como cultura são a dialética que movimenta, interage e dá sentido à vida e às práticas na pesca, que, por sua vez refletem-se em saberes que, pautados pela 
tradição, permitem aos pescadores se relacionem com o meio onde estão inseridos de maneira íntima, proporcionando a criatividade e a sabedoria." (MORAES, 2007, p.90)

A espécie de camarão que Dila se refere, nesta entrevista, é o camarão de água doce (Macrobrachium amazonicum), comum da região da Ilha. As informações sobre a atividade foram presenciadas inúmeras vezes. Inclusive, registra que parte de sua renda mensal, vem da pesca, ela faz a pesca, a retirada das redes de determinados locais para captura do pescado, e o beneficia (captura, fileta e salga o pescado para venda).

\section{Letramento e Prática Docente}

Destaca-se o letramento, que pode ser definido segundo ( SOARES, 2003, p.53) “... o resultado da ação de ensinar ou de aprender a ler e escrever: o estado ou a condição que adquiri um grupo social ou um indivíduo como conseqüência de ter-se apropriado da escrita". Estará presente elementos do conecimento, aplicadopara ensinar, na década de 70, e hoje, com a presença de Escola na Ilha

O professor da Ilha Tabatinga, na década de 70, foi seu Ceará, que dizia haver todo trabalho, para ensinar, os alunos iam buscá-lo no trapiche, iam de canoa, buscá-lo em frente da cidade, para levá-lo até a ilha. Ele se autodenomina, “... Eu era o doutrinador!Ensinava, a matemática e a prova dos noves, Meu aluno! Era pescador, aprendia até a passar troco..."

Quando indagado, sobre a sua sala de aula. Seu Ceará: _ "Minha sala de aula, era a casa dos alunos, a cada mês ficávamos em uma casa diferente. Quem tinha interesse pagava e eu ensinava"!

Evidencia-se nas lembranças a compreensão das experiências passadas, através de reconstituições do tempo, o qual foi capaz de fazer, podendo ser confirmado ou diferenciado, com diferenças e semelhanças por que são memórias de um tempo histórico, no qual ensinar as primeiras letras, era aprender a desenhar o nome, e os números. Pórem, só seria possível, quando se chegava aos pescadores. Pelos caminhos líquidos da comunidade.

Atualmente na Ilha de Sirituba, Dila afirma: “_é muito gratificante, pois ensinar o pescador com anos de experiência é aprender todo dia", mas que não é fácil, pois ela se ver sozinha em sala, com alunos de $1^{\circ}$ e $2^{\circ}$ ano que precisam, aprendem a ler, e outros precisam avançar de séries, fala que ao realizar o planejamento educacional de suas atividades, ela pensa nas duas séries, e como vai utilizar a retórica e conhecimentos dos pescadores, em sala de aula.

Leitura e escrita formam juntas um diferencial no processo de ensinoaprendizagem que alguns denominam de letramento. Processo pelo qual, os indivíduos iniciam em seu convívio familiar e se perpetua para os demais estágios da vida. Esse processo de alfabetização deve ser contínuo, dentro e fora da sala de aula.

Uma das maneiras que utilizou para falar de educação ambiental com os dos grupos foi sobre os resíduos de pescados que após pescados não podem serdescartados na natureza, que devem servi de alimentos a outras espécies, ou utilizados de outras maneiras para sustentabilidade ambiental, ao ouvir seus alunos comentando: "quando 
venho da pesca, não quero nem saber, o que sobra, já vendi meu peixe, jogo, tudo nas águas, papel, sacola..."leitura de mundo associada à realidade de sala de aula, evidenciando seu contexto interdisciplinar como ressalta Luck, (apud Pavianni)

Cabe agora, pois, estabelecer um sentido mais abrangente,
aprofundado e significativo às experiências pedagógicas, para as quais
ainterdisciplinaridade muito tem a contribuir. Isso porque a realidade
coma qual o ensino propõe-se a levar o aluno a conhecer "É um
fenômeno múltiplo, diversificado, e todos os conhecimentos e
interpretações, enquanto só explicam uma parte da realidade,
permanecem sempre inacabados. (Luck, 1998, p 53)

E ao falar em aprender, serão considerados os diversos saberes, pois estes sujeitos estão inseridos num contexto letrado, se considerarmos que alguns podem ou não saber ler e escrever, porém podem deter habilidades em suas atividades pesqueiras que transcendem o conhecimento acadêmico.

\section{Conclusões}

Observando que a pesca é uma atividade extrativa e que varia ao decorrer do ano, é necessário analisá-la com caráter humanístico, assim como sua análise, demonstrando que o conhecimento pode ser construído com a troca de experiências, uma vez que esta atividade já faz parte da história cultural de Abaetetuba.

Ao analisar a prática educacional, e a condução do processo educativo na região amazônica, que se depara entre o passado e o presente, com mudanças significativas, a respeito do conhecimento e da prática pedagógica, mesmo que sem apoio pedagógico eficiente, a memória docente de quem trabalha na atividade pesqueira, reconstrói novos horizontes para história da educação no qual, o papel do professor, e do pescadortransforma e se transforma, em locais de avenidas líquidas sem energia elétrica, e com horários condizentes, com o poder financeiro dos educandos, o qual se transforma ao longo do tempo, para dar lugar ao ensino de qualidade as poulações riberinhas na região.

\section{Referências bibliográficas:}

ARANHA, Maria Lúcia de Arruda. História da educação e da pedagogia: geral e Brasil/ . $3^{\text {a }}$ Ed. Ver. Ampliada- São Paulo: Moderna, 2006

BEGOSSI, Alpina (org.) Ecologia de pescadores da Mata Atlântica e da Amazônia/: participantes, Andrea Leme.. [ET AL.]. - São Paulo: Hucitec: Nepam/Unicamp: Nupaub/USP: FAPESP, 2004.

BOSI, Ecléa Memória e sociedade: Lembranças dos velhos/ Ecléa Bosi. -3.ed.-São Paulo: Companhia das Letras, 1994.

BOSI, Ecléa O tempo vivo da memória: ensaios de psicologia social/ Ecléa Bosi. _ São Paulo: Ateliê Editorial, 2003. 
BURKE, Peter. "História como memória social".In: Variedades de história cultural. Rio de Janeiro: Civilização Brasileira. 2000, .

Diagnóstico da pesca e da Aqüicultura do Estado do Pará 2007. Secretaria de Estado de pesca e Aqüicultura. Sepaq. Governo do Estado. 2008.

FREIRE, Paulo. Pedagogia da autonomia: saberes necessários á prática educativa. São Paulo: Paz e Terra, 1996.

HAGE, Salomão Mufarrej (Org.) Educação do campo na Amazônia: retratos de realidade das escolas multisseriadas no Pará /. - Belém: Gráfica e Editora Gutemberg, Ltda, 2005.

LE GOFF, Jacques. “Memória”.In: História e Memória. Campinas: Ed. UNICAMP, 1994.

LUCK, Heloísa. Pedagogia Interdisciplinar: fundamentais teóricos-metodologicas. 2 ed. Petrópolis. RJ: vozes, 1994.

MORAES, Sérgio Cardoso de. Uma Arqueologia dos Saberes da pesca: Amazônia e Nordeste / Sérgio Cardoso de Moraes. _ Belém: EDUFPA, 2007.

OLIVEIRA, Ivanilde Apoluceno de oliveira. Filosofia da educação: reflexos e debates. Belém: UNAMA, 2003.

\footnotetext{
Notas

${ }^{1}$ Pedagoga- Técnica em Aquicultura-Professora da Área de Recursos Pesqueiros IFPA - Abaetetuba PA. Mestranda em História e Memória da Educação ( UFCE -CE).

2 "defini-se como pesca artesanal,a atividade exercida por produtores autônomos ou com relações de trabalho em parcerias, que utilizam pequenas quantias de capital e meios de produção simples, com tecnologia e metodologia da captura não mecanizada e baseada em conhecimentos empíricos".

3 Sujeitos do campo: populações tradicionais, pescadores, indígenas, ribeirinhos, quilombolas, agricultores.
}

Recebido em: $\quad 31 / 08 / 2011$

Aprovado em: 10/09/2011 